
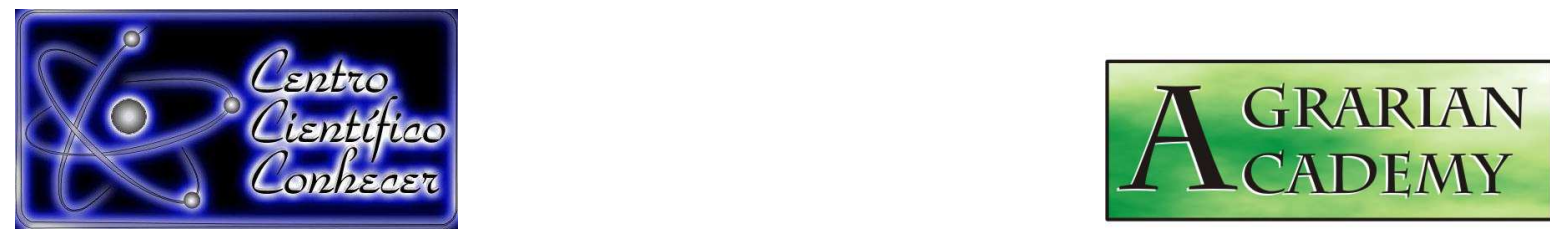

\title{
ÁCIDO INDOLBUTíRICO E SUBSTRATOS NO DESENVOLVIMENTO DE ESTACAS DE UMBUZEIRO EM TRÊS ESTÁDIOS FENOLÓGICOS
}

\author{
Elma Machado Ataíde, Marcelo de Souza Silva², Jackson Mirellys Azevêdo Souza ${ }^{3}$, \\ Débora Costa Bastos ${ }^{4}$ \\ ${ }^{1}$ Dra., Universidade Federal Rural de Pernambuco, Unidade Acadêmica de Serra \\ Talhada, PE, Serra Talhada-PE, Brasil. Email: elma.ataide@ufrpe.br \\ ${ }^{2}$ Doutorando, Universidade Estadual Paulista, Botucatu, SP, Brasil \\ Pós-Doutorando, Universidade Estadual Paulista, Botucatu, SP, Brasil \\ ${ }^{3}$ Dra., Embrapa Semiárido, Petrolina, PE, Brasil
}

Recebido em: 30/11/2017 - Aprovado em: 15/12/2017 - Publicado em: 31/12/2017 DOI: 10.18677/Agrarian Academy 2017b3

\begin{abstract}
RESUMO
As frutas nativas passaram a ser vista como excelente alternativa para os agricultores das diversas regiões do país, principalmente, do semiárido nordestino. Contudo, observa-se que muitas espécies do bioma caatinga sofrem devastação, especialmente o umbuzeiro. Portanto, é importante difundir tecnologias com vista a preservação destas espécies, especialmente voltadas para produção de mudas pelo método vegetativo, que possibilitará maior uniformidade e produtividade das espécies nativas. Desta forma, objetivou-se neste trabalho avaliar o uso de ácido indolbutirico e diferentes substratos e estádios fenológicos no enraizamento de estacas de umbuzeiro. O experimento foi conduzido na Unidade Acadêmica de Serra Talhada em condições em viveiro telado com $50 \%$ de sombreamento. $O$ delineamento experimental foi inteiramente casualizado, sendo quatro concentrações de AIB e três tipos de substratos, com três repetições com 10 estacas por parcela. $O$ experimento foi repetido em três épocas de coleta (setembro, novembro e fevereiro), avaliando-se de forma isolada cada uma. Com base nos principais resultados foi possível inferir que o uso de AIB nas doses concentrações utilizadas não promoveu enraizamento e brotações satisfatórias das estacas de umbuzeiros. Avaliando-se os substratos, verifica-se que a areia em associação com a concentração de $9.000 \mathrm{mg} \mathrm{L}^{-1}$ de $\mathrm{AIB}$, proporcionou melhores resultados de enraizamento e desenvolvimento das brotações.
\end{abstract}

PALAVRAS-CHAVE: auxina, reguladores vegetais, Spondias tuberosa Arruda. 


\title{
INDOLYLBUTYRIC ACID AND SUBSTRATES IN ROOTING OF UMBUZEIRO CUTTINGS AT DIFFERENT PHENOLOGICAL STAGES
}

\begin{abstract}
Native fruits have come to be seen as an excellent alternative for farmers in different regions of the Brazil, mainly the semi-arid northeast. However, it is observed that many species of caatinga biome suffer devastation, especially umbuzeiro. Therefore, it is important to spread technologies for the preservation of these species, especially focused on the production of seedlings by vegetative method, which will enable greater consistency and productivity of native species. Thus, this study aimed to evaluate the use of indolebutyric acid and substrates in umbuzeiro rooting cuttings at different phenological stages. The experiment was conducted at the Serra Talhada Academic Unit under conditions in a nursery with $50 \%$ shading. The experimental design was completely randomized, with four concentrations of IBA and three substrates, with three replicates and 10 cuttings per plot. The experiment was carried out in three collection seasons (September, November and February), evaluating each one separately. The use of AIB did not promote the satisfactory development of roots and shoots of umbuzeiros cuttings. Manure from goats and coconut fiber should not be used for cutting the umbuzeiro. The use of sand in association with the concentration of $9,000 \mathrm{mg} \mathrm{L}-1$ of IBA, although not satisfactory, provided better rooting results and development of the shoots.
\end{abstract}

KEYWORDS: auxin, plant growth regulators, Spondias tuberosa Arruda.

\section{INTRODUÇÃO}

Dentre as espécies nativas do semiárido brasileiro com potencial de cultivo, merece destaque o umbuzeiro (Spondias tuberosa Arruda - Anacardiaceae), espécie endêmica do Bioma Caatinga, com grande demanda de mercado. Os frutos são ricos em vitamina $\mathrm{C}$, apreciados para o consumo in natura, como industrializados na forma de sucos, doces, geléias, sorvete e umbuzada. O cultivo do umbuzeiro constitui-se, atualmente, em uma perspectiva promissora de expansão no semiárido nordestino, já é explorado de forma extrativista e contribui para o rendimento familiar dos agricultores locais (MERTENS et al., 2016).

$\mathrm{O}$ setor agrícola, no que diz respeito à coleta, beneficiamento e comercialização de umbu, gerou em torno de 11,162 milhões de reais no ano de 2016, com volume de produção de 8,39 mil toneladas (IBGE, 2017). As principais regiões produtoras localizam-se no Sudoeste e Norte da Bahia, cujos produtos são comercializados nos mercados mais sofisticados do Brasil e também no exterior (COOPERCUC, 2017). No Brasil, a comercialização é realizada, principalmente, em feiras livres na forma de fruta fresca e/ou destinado às agroindústrias para produção de polpa.

A preservação das frutíferas nativas, aliada a maior exploração do potencial destas culturas é uma excelente opção para a agricultura familiar do semiárido brasileiro, onde há diversidade de espécies com potencial de mercado. Contudo, o uso indiscriminado dos recursos do bioma caatinga e o crescente desmatamento têm colocado em risco a utilização das espécies nativas (XAVIER et al., 2011), sobretudo o umbuzeiro, o qual também sofre com a exploração de suas raízes tuberosas (xilopódios) para a produção de um doce local, denominado de cafofa.

Neste cenário, o desenvolvimento de tecnologias que permitam maior facilidade de propagação e produção de mudas destas espécies constitui em 
importante ferramenta. No caso específico do umbuzeiro, a propagação via sementes ainda é o principal método utilizado, todavia, as mudas originadas por sementes apresentam alta juvenilidade e grande variabilidade genética, de modo que a propagação vegetativa torna-se uma alternativa para produção de mudas com período reprodutivo antecipado e maior homogeneidade (DUTRA et al., 2012). Dentre os métodos de propagação vegetativa, para o umbuzeiro, destaca-se a estaquia.

O sucesso da técnica de estaquia depende do enraizamento das estacas, o qual pode ser afetado por diversos fatores. Conforme Denaxa et al. (2012), estes fatores podem ser endógenos, como o balanço hormonal e nutricional da planta matriz, sobretudo a concentração endógena de auxina, e fatores externos, como por exemplo, as condições ambientais e o substrato utilizado.

A condição nutricional e o balanço hormonal das estacas é diretamente afetada pela época de coleta e fase fenológica das estacas, o que evidencia a importância da interação entre estes fatores para a produção de mudas pelo método de estaquia. Para espécies do gênero Spondias, as estacas devem ser coletadas antes da emissão das brotações, já que na fase de desenvolvimento reprodutivo, as reservas, como os carboidratos, as proteínas e os aminoácidos, são direcionadas para formação das flores e frutos (SOUZA; ARAÚJO, 1999).

Contudo a utilização de reguladores vegetais é uma prática que pode auxiliar na produção de mudas de qualidade (TECCHIO et al., 2015). Dentre os reguladores, a auxina é o responsável pela promoção do enraizamento de estacas, promovendo maior comprimento e volume de raízes, o que auxilia na sobrevivência das mudas quando levadas à campo (DAS; PRASAD, 2014). Uma das principais auxinas sintéticas utilizadas é o ácido indolbutírico (AIB).

Em virtude do difícil enraizamento das estacas de umbuzeiro, poucos são os trabalhos cujos resultados demonstram altos índices de enraizamento. Gomes et al. (2008), em experimento com a cultura do umbuzeiro, avaliaram três doses de ethephon (14,5, 40 e $\left.100 \mathrm{mg} \mathrm{L}^{-1}\right)$, aplicado na copa 30 dias antes da coleta, seguido de tratamento das estacas com AIB (3000 e 5127,65 $\mathrm{mg} \mathrm{L}^{-1}$ ). No entanto observaram apenas enraizamento das estacas tratadas com AIB isolado. Já Rios et al. (2012), testaram tamanho de estacas $(10$ e $20 \mathrm{~cm}$ ) de umbuzeiro, concentrações de AIB $\left(0,1.500,300,4.500\right.$ e $6.000 \mathrm{mg} \mathrm{L}^{-1}$ ) e duas épocas de coleta (março e setembro) e verificaram melhor enraizamento das estacas coletadas em março, com $20 \mathrm{~cm}$ de comprimento e com a concentração de AIB de $6.000 \mathrm{mg} \mathrm{L}^{-1}$, contudo, 0 percentual de enraizamento foi de cerca de $30 \%$ apenas.

Em relação aos substratos, conforme Dutra et al. (2012), estes também possuem ligação direta com o enraizamento e podem auxiliar e potencializar tal característica. Dentre as principais finalidades de um bom substrato, destacam-se o fornecimento de água, oxigênio e nutrientes (LIMA et al., 2010), o que dependerá das características físicas e químicas do mesmo. Existem diferentes substratos disponíveis no mercado para produção de mudas frutíferas, como o Plantmax ${ }^{\circledR}$, porém são poucos os estudos com relação ao seu uso para a produção de mudas de umbuzeiro.

Face ao exposto, estudos que visem a melhoria das técnicas de propagação do umbuzeiro são de grande relevância, especialmente aquelas relacionadas à épocas de coletas (fases fenológicas), substratos e concentrações de AIB, já que os resultados apresentados por diversos autores ainda são inconsistentes. Desta forma, objetivou-se neste trabalho avaliar o uso de diferentes concentrações de 
ácido indolbutírico, substratos e estádios fenológicos no enraizamento de estacas de umbuzeiro.

\section{MATERIAL E MÉTODOS}

O trabalho foi conduzido em viveiro telado com $50 \%$ de sombreamento, na Unidade Acadêmica de Serra Talhada da Universidade Federal Rural de Pernambuco, município de Serra Talhada-PE, localizada nas coordenadas de $07^{\circ} 59^{\prime} 31^{\prime \prime}$ de latitude e $38^{\circ} 17^{\prime} 54^{\prime \prime}$ de longitude, com altitude de $530 \mathrm{~m}$.

O clima da região é classificado como semiárido, caracterizado por chuvas concentradas nos meses de março e abril, com média de $550 \mathrm{~mm}$ anual. A temperatura média anual é de $32,0 \stackrel{\circ}{\circ} \mathrm{C}$ e umidade relativa do ar de $62,8 \%$. O solo da região é do tipo Latossolo Vermelho Amarelo e a vegetação caatinga.

Adotou-se a propagação vegetativa do umbuzeiro pelo método da estaquia, utilizando-se estacas em três fases fenológicas: estádios de dormência (setembro), reprodutivo (novembro), e vegetativo (fevereiro). As estacas foram coletadas da planta adulta do Parque Estadual Mata da Pimenteira, Serra Talhada, PE, previamente georeferenciadas por GPS. Cada fase fenológica foi avaliada de forma isolada, variando-se as concentrações de AIB e o tipo de substrato como descrito a seguir, perfazendo-se três experimentos. Todas as etapas referentes à metodologia foram realizadas de forma semelhante em cada uma das coletas (fases fenológicas).

As estacas do umbuzeiro nos três estádios foram coletadas no início da manhã, evitando-se perda de água por transpiração, e acondicionadas em caixas térmicas. Em seguida, transportadas para o Laboratório de Química da Unidade Acadêmica de Serra Talhada, onde se procedeu a padronização do tamanho da estaca de $20 \mathrm{~cm}$ (RIOS et al., 2012), seguido do corte reto, no ápice e em bisel, na base, com auxilio de tesoura de poda. Posteriormente, as estacas foram submetidas à aplicação dos tratamentos com AIB, por imersão da parte basal a $2 \mathrm{~cm}$, por 10 segundos, nas concentrações de $3.000,6.000$ e $9.000 \mathrm{mgL}^{-1}$, a testemunha em solução hidroalcoólica. O preparo da solução de AIB foi em solução hidroalcoólica $(50 \% \mathrm{v} / \mathrm{v})$, para melhor diluição do produto.

Após a aplicação dos tratamentos, as estacas foram acondicionadas em bandejas plásticas com $2 / 3$ do comprimento inseridos em três tipos de substratos, sendo areia lavada, esterco de caprino curtido e substrato comercial composto de fibra de coco, todos previamente esterilizados em autoclave por 60 minutos a $120^{\circ} \mathrm{C}$. Após o estaqueamento nos diferentes substratos, as bandejas foram transferidas para o viveiro telado, e manteve a irrigação diária.

As avaliações foram realizadas aos 90 dias após a aplicação dos tratamentos. As características avaliadas foram: percentual de estacas enraizadas e com brotações; comprimento da maior raiz e das brotações $(\mathrm{mm})$, aferidos com régua graduada; número de raízes e de brotações, obtida por meio da contagem individual por estaca; massa fresca das estacas, das brotações e das raízes, determinada com auxílio de balança analítica com precisão de 0,001g; e massa seca das estacas, das brotações e das raízes, com auxílio de balança analítica com precisão de 0,001g, após secagem em estufa a $70^{\circ} \mathrm{C}$ por 72 horas.

$O$ delineamento experimental adotado foi inteiramente casualizado para as três épocas, perfazendo-se para cada uma delas, um fatorial $4 \times 3$, sendo o primeiro fator as concentrações de AIB $\left(0,3.000,6.000\right.$ e $\left.9.000 \mathrm{mg} \mathrm{L}^{-1}\right)$, e o segundo os substratos (areia lavada, esterco de caprino curtido e fibra de coco). Utilizou-se em cada um dos experimentos, três repetições com 10 estacas por parcela, totalizando 360 estacas avaliadas em cada um dos experimentos (épocas de coleta). Os dados 
obtidos foram submetidos à análise de variância e quando significativos, aplicou-se teste de regressão para o fator concentrações de AIB e o teste Tukey, ao nível de $5 \%$ de probabilidade, para o fator tipo de substrato.

\section{RESULTADOS E DISCUSSÃO}

\section{Experimento 1}

Com base nos resultados da análise de variância, observou-se que houve interação significativa $(p<0,05)$ entre os fatores substratos e concentrações de AIB para o número de raízes, matéria seca de brotações, matéria seca de estacas, porcentagem de estacas enraizadas e porcentagem de brotações (Tabela 1). Quando avaliados os fatores isolados, verificou-se efeito significativo $(p<0,01)$ dos substratos para a maioria das características analisadas, com exceção da massa fresca das brotações e massa fresca e seca das estacas. Já em relação ao fator doses de AIB isolado, observou-se efeito significativo apenas para massa fresca e seca das estacas (Tabela 1). Assim como neste trabalho, Rios et al. (2012) não verificaram efeito do uso de AIB sobre o número de brotações por estaca, o que pode ser devido ao fato da brotação lateral das estacas estar relacionada ao conteúdo de outro hormônio endógeno, a citocinina.

TABELA 1. Valores do teste $F$, graus de liberdade (GL), coeficientes de variação (CV) e médias do comprimento de raízes (CR) e brotações (CB), número de raízes (NR) e brotações (NB), massa fresca e seca de raízes (MFR e MSR), brotações (MFB e MSB) e estacas (MFE e MFB), respectivamente, de estacas de umbuzeiro coletadas em estádio de dormência. Serra Talhada - PE. 2017.

\begin{tabular}{|c|c|c|c|c|c|c|c|c|c|c|c|c|c|c|}
\hline FV & $\mathrm{GL}$ & $\begin{array}{l}\mathrm{EE} \\
(\%)\end{array}$ & $\begin{array}{l}\text { EB } \\
(\%)\end{array}$ & $\begin{array}{c}\text { ESRB } \\
(\%)\end{array}$ & $\begin{array}{c}\mathrm{CR} \\
(\mathrm{cm})\end{array}$ & $\begin{array}{c}\mathrm{CB} \\
(\mathrm{cm})\end{array}$ & NR & NB & MFR & MFB & MFE & MSR & MSB & MSE \\
\hline Substratos - A & 2 & $15,3^{* \star}$ & $27,0^{* *}$ & $46,2^{* *}$ & $8,3^{* *}$ & $32,3^{* *}$ & $15,3^{* *}$ & $27,0^{* *}$ & $7,9^{* *}$ & $2,9^{\text {ns }}$ & $2,0^{\mathrm{ns}}$ & $6,8^{* *}$ & $26,8^{* *}$ & $0,2^{\mathrm{ns}}$ \\
\hline Doses - B & 3 & $2,9^{\mathrm{ns}}$ & $0,5^{\mathrm{ns}}$ & $0,3^{\text {ns }}$ & $1,6^{\mathrm{ns}}$ & $1,0^{\mathrm{ns}}$ & $2,9^{\text {ns }}$ & $0,6^{\mathrm{ns}}$ & $1,5^{\mathrm{ns}}$ & $0,6^{\mathrm{ns}}$ & $4,1^{*}$ & $1,2^{\text {ns }}$ & $1,6^{\text {ns }}$ & $22,0^{* *}$ \\
\hline$A \times B$ & 6 & $2,7^{*}$ & $1,6^{\mathrm{ns}}$ & $5,7^{\star *}$ & $1,8^{\mathrm{ns}}$ & $2,3^{\mathrm{ns}}$ & $2,7^{*}$ & $1,7^{\mathrm{ns}}$ & $1,6^{\mathrm{ns}}$ & $1,6^{\mathrm{ns}}$ & $2,2^{\mathrm{ns}}$ & $1,0^{\text {ns }}$ & $6,2^{\star *}$ & $10,4^{* *}$ \\
\hline CV (\%) & & 12,7 & 58,2 & 16,2 & 17,9 & 57,8 & 12,6 & 58,1 & 18,9 & 18,5 & 22,6 & 16,5 & 61,7 & 10,0 \\
\hline Média & & 2,3 & 6,3 & 73,3 & 1,4 & 2,2 & 0,2 & 0,6 & 0,04 & 0,07 & 4,9 & 0,01 & 0,01 & 2,9 \\
\hline
\end{tabular}

Em relação à interação entre os substratos e as concentrações de AIB, observou-se que a utilização da areia para a propagação de estacas de umbuzeiro coletadas em estádio de dormência resultou no aumento linear para o número de raízes por estaca em função da elevação nas concentrações de AIB, enquanto que as médias desta variável não se ajustaram a nenhum modelo matemático quando utilizado os substratos fibra de coco e esterco de caprino (Figura 1A). O maior número de raízes por estaca é uma variável importante para a produção de mudas, visto que o maior volume de raízes resultará em melhor estabelecimento das mudas no campo (FRANCO et al., 2005). De acordo com Das e Prasad (2014), a auxina é responsável pela produção de raízes mais finas e numerosas, auxiliando na absorção de água e nutrientes. 
Para a massa seca das brotações $(\mathrm{g})$, verificou-se maiores valores com a interação entre o substrato areia e a concentração de AIB de $9.000 \mathrm{mg} \mathrm{L}^{-1}$ (Figura 1B). Enquanto que com o substrato fibra de coco, observou-se efeito quadrático dos resultados da massa seca das brotações em função da aplicação das diferentes concentrações de AIB, com maior média obtida na concentração de $4.500 \mathrm{mg} \mathrm{L}$ ${ }^{1}$ AIB. Não houve ajuste das médias da massa seca das brotações para o substrato esterco de caprino em função da aplicação de AIB (Figura 2B).

Quando analisada a interação dos substratos com as concentrações de AIB sobre a massa seca das estacas coletadas em estádio de dormência, verificou-se comportamento linear crescente nas médias dessa variável nos substratos areia e esterco caprino, com maior valor obtido na concentração de $9.000 \mathrm{mg} \mathrm{L}^{-1}$ de AIB (Figura 1C). Já em relação aos resultados da massa seca das estacas (g) em função da utilização do substrato fibra de coco, foi possível observar ajuste quadrático dos resultados em função da aplicação das diferentes concentrações de AIB utilizadas, com maior valor de massa seca das estacas na dose de $4.420 \mathrm{mg} \mathrm{L}^{-1}$ (Figura 1C).

Em relação à porcentagem de enraizamento, verificou-se que quando utilizado o substrato areia, obteve-se acréscimo linear das médias com o aumento das concentrações de AIB, alcançando-se a maior média $(11,1 \%)$ na concentração de $9.000 \mathrm{mgL}^{-1}$. As porcentagens de enraizamento com os substratos esterco de caprinos e fibra de coco foram inferiores às do substrato areia, independente da concentração de AIB utilizada e não se ajustaram aos modelos linear e quadrático (Figura 1D). As porcentagens de enraizamento observadas neste trabalho, mesmo com o substrato areia, são consideradas baixas, visto que em outros trabalhos, obtiveram-se resultados superiores com o uso do AIB em estacas de umbuzeiro, como Rios et al. (2012), que observaram enraizamento superior a $30 \% \mathrm{com}$ a concentração de $6.000 \mathrm{mgL}^{-1}$ de AIB. Vale ressaltar que diversos fatores podem afetar o enraizamento de estacas, sejam endógenos, como a condição hormonal, ou mesmo exógenos, como os fatores ambientais (DENAXA et al., 2012). Deste modo, considerando que as estacas estavam em estádio de dormência, é possível que houvesse grande quantidade de hormônios, como o ácido abscísico e etileno, os quais podem ter suprimido o efeito do AIB aplicado. 

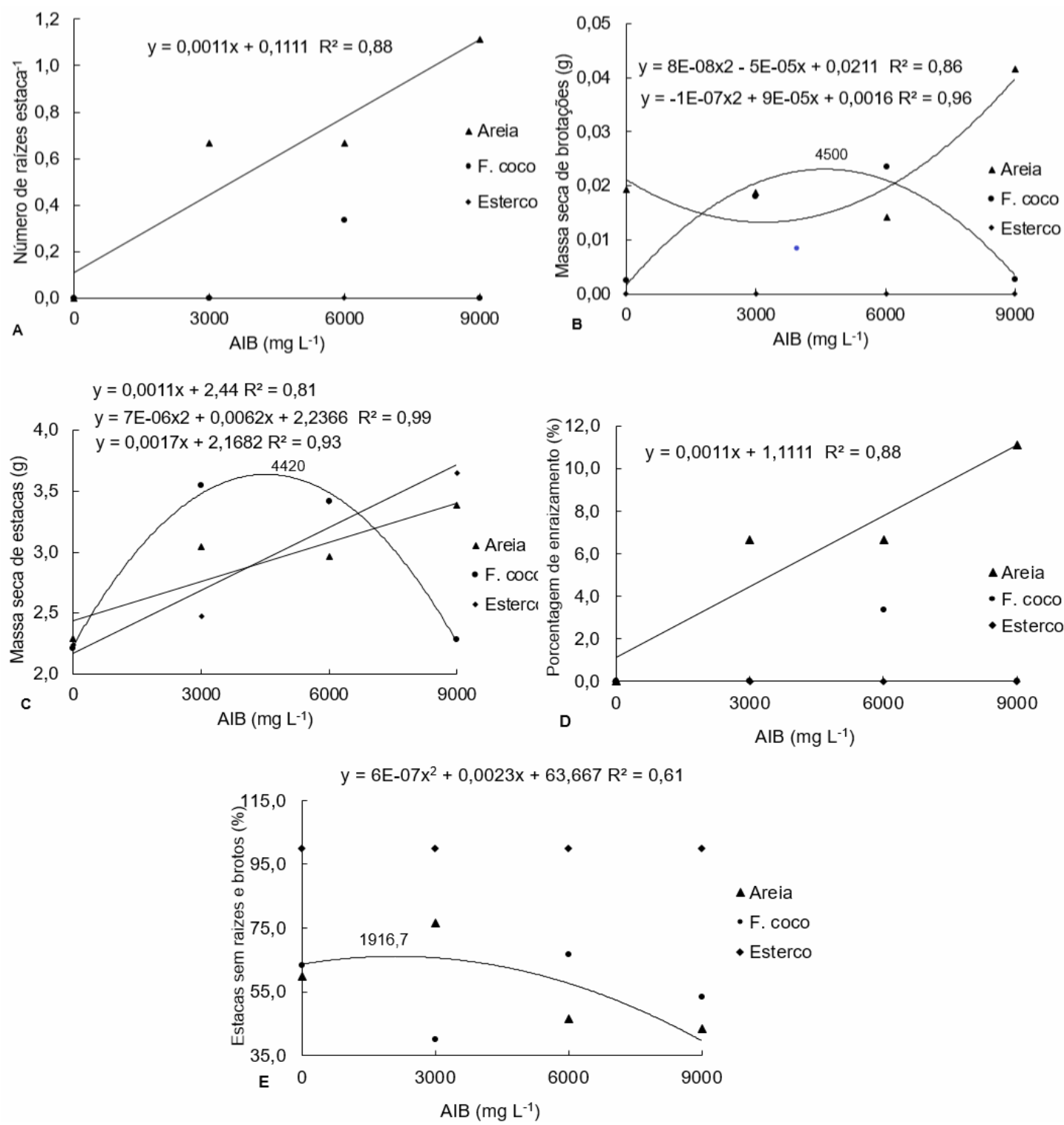

FIGURA 1. Número de raízes por estaca (A), massa seca de brotações(B) e de estacas (C), porcentagem de enraizamento (D) e porcentagem de estacas sem raízes e brotações (E) de estacas de umbuzeiro coletadas em estádio de dormência e enraizadas em diferentes substratos e concentrações de AIB. Serra Talhada - PE. 2017.

Avaliando-se a interação entre os substratos e as concentrações de AIB para a porcentagem de estacas que não emitiram raiz e nem brotações, observou-se que a utilização do substrato areia permitiu a obtenção de menores valores que os demais substratos, para o qual os valores decresceram de forma quadrática com o aumento das doses de AIB. Somente com a dose de $3.000 \mathrm{mg} \mathrm{L}^{-1}$ de AIB, que o substrato fibra de coco apresentou menor média de estacas sem raízes e brotações que o substrato areia. As médias observadas para os substratos fibra de coco e esterco de caprinos não se ajustaram a nenhum dos modelos de equação avaliados (Figura 1E). A elevada porcentagem de estacas sem raízes e brotações obtida com o substrato esterco de caprino, independente da dose de AIB, demonstra que este substrato não é recomendado para a produção de mudas de umbuzeiro.

Quanto ao fator substrato isolado, a utilização de areia proporcionou melhores resultados de comprimento da raiz e das brotações e massa fresca e seca de raízes, AGRARIAN ACADEMY, Centro Científico Conhecer - Goiânia, v.4, n.8; p. 27 2017 
quando comparadas com os demais substratos utilizados, com valores médios de $3,8 \mathrm{~cm}, 4,22 \mathrm{~cm}, 0,10 \mathrm{~g}$ e $0,02 \mathrm{~g}$, respectivamente (Tabela 2). Observou-se que as estacas no substrato esterco de caprino não apresentaram brotações, diferindo significativamente dos demais substratos utilizados (Tabela 2). Tal resultado é importante, visto a facilidade e menor custo para obtenção da areia, quando comparado ao substrato comercial, diminuindo assim o custo para a produção das mudas. Para a porcentagem de estacas brotadas, não houve diferença entre os substratos areia e fibra de coco, os quais apresentaram médias de 10,1 e 8,7\%, respectivamente.

Embora o esterco de caprino seja um recurso em abundância e de fácil aquisição na região semiárida nordestina, em virtude da forte atividade de criação destes animais, a utilização na propagação de estacas de umbuzeiro no estádio de dormência não foi interessante pelos resultados obtidos quanto ao enraizamento e brotações.

TABELA 2. Médias do comprimento de raízes (CR) e brotações (CB), porcentagem de estacas brotadas (PEB), número de brotações (NB) e massa fresca e seca de raízes (MFR e MSR) de estacas de umbuzeiro coletadas em estádio de dormência. Serra Talhada - PE. 2017.

\begin{tabular}{ccccccc}
\hline Substratos & $\begin{array}{c}\text { CR } \\
(\mathrm{cm})\end{array}$ & $\begin{array}{c}\text { CB } \\
(\mathrm{cm})\end{array}$ & $\begin{array}{c}\text { PEB } \\
(\%)\end{array}$ & NB & $\begin{array}{c}\text { MFR } \\
(\mathrm{g})\end{array}$ & $\begin{array}{c}\text { MSR } \\
(\mathrm{g})\end{array}$ \\
\hline Areia & $3,80 \mathrm{a}$ & $4,22 \mathrm{a}$ & $10,1 \mathrm{a}$ & $1,01 \mathrm{a}$ & $0,10 \mathrm{a}$ & $0,02 \mathrm{a}$ \\
Fibra de coco & $0,42 \mathrm{~b}$ & $2,49 \mathrm{~b}$ & $8,7 \mathrm{a}$ & $0,87 \mathrm{a}$ & $0,01 \mathrm{~b}$ & $0,002 \mathrm{~b}$ \\
Esterco curtido & $0,00 \mathrm{c}$ & $0,00 \mathrm{c}$ & $0,0 \mathrm{~b}$ & $0,00 \mathrm{~b}$ & $0,00 \mathrm{~b}$ & $0,00 \mathrm{~b}$ \\
\hline
\end{tabular}

Médias seguidas da mesma letra nas colunas não diferem estatisticamente entre si, teste Tukey $5 \%$ de probabilidade.

Em relação ao fator concentrações de AIB isolado, para as estacas coletadas em estádio de dormência, verificou-se que a massa fresca das estacas aumentou de forma linear com o aumento das concentrações de AIB (Figura 1).

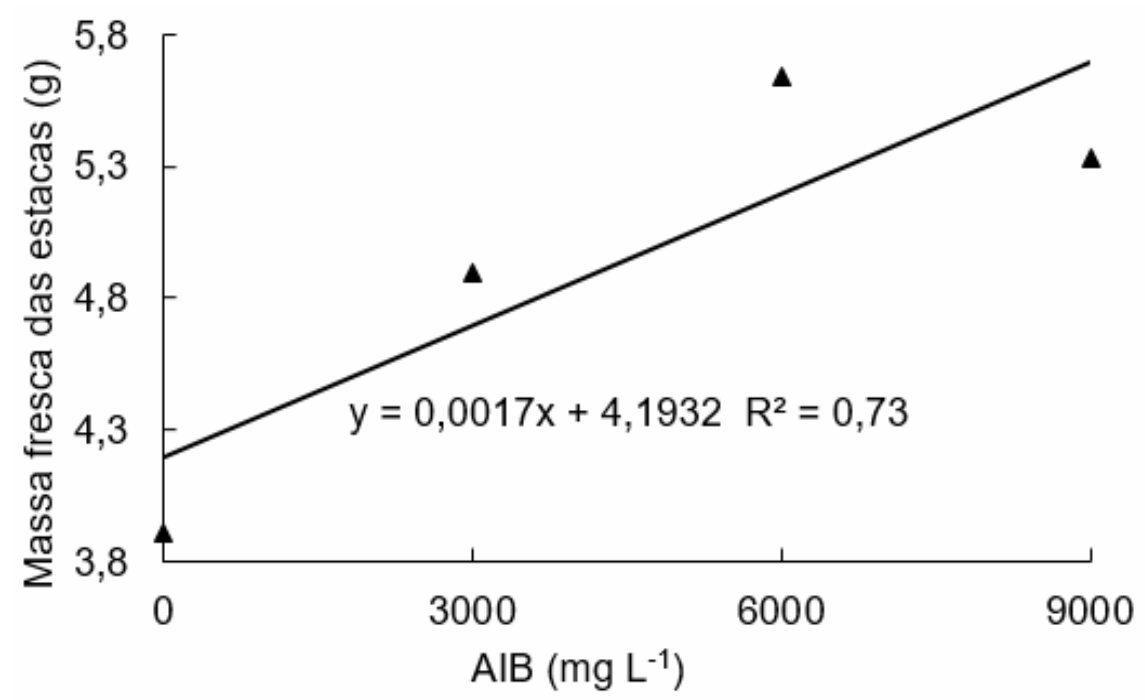

FIGURA 2. Valores de massa fresca de estacas $(\mathrm{g})$ de estacas de umbuzeiro coletadas em estádio de dormência e submetidas a aplicação de diferentes concentrações de AIB. Serra Talhada - PE. 2017. 


\section{Experimento 2}

Quando analisados os resultados das estacas de umbuzeiro coletadas em estádio reprodutivo, não foi observada a formação de raízes nas estacas independente do substrato ou das diferentes concentrações de AIB utilizadas. Este resultado pode estar relacionado às altas concentrações de hormônios relacionados ao desenvolvimento floral, os quais podem suprimir o efeito da auxina (TAIZ; ZEIGER, 2013), afetando diretamente o enraizamento das estacas, fato pelo qual houve maior desenvolvimento das brotações em detrimento do desenvolvimento de raízes. De acordo com Peña et al. (2015), o desenvolvimento de brotações afeta negativamente o enraizamento das estacas, visto que novas brotações, assim como flores e frutos são os principais drenos da planta.

Para as demais variáveis, verificou-se efeito significativo para a interação entre os substratos e as concentrações de AIB somente para número de brotações e massa fresca de brotações, todavia houve efeito isolado do fator substratos para todas as variáveis, enquanto que para o fator concentrações de AIB não houve efeito, somente para a massa seca de brotações (Tabela 3).

TABELA 3. Valores do teste $F$, graus de liberdade (GL), coeficientes de variação (CV) e médias do comprimento de brotações (CB), número de raízes (NR) e brotações (NB), massa fresca e seca de raízes (MFR e MSR), brotações (MFB e MSB) e estacas (MFE e MSB), respectivamente, de estacas de umbuzeiro coletadas em estádio reprodutivo. Serra Talhada - PE. 2017.

\begin{tabular}{ccccccccc}
\hline FV & GL & $\begin{array}{c}\text { CB } \\
(\mathrm{cm})\end{array}$ & NB & $\begin{array}{c}\text { PB } \\
(\%)\end{array}$ & MFB & MFE & MSB & MSE \\
\hline Substratos - A & 2 & $13,4^{* *}$ & $469,0^{* *}$ & $21,9^{* *}$ & $22,7^{* *}$ & $7,4^{* *}$ & $12,8^{* *}$ & $4,35^{* *}$ \\
Doses - B & 3 & $3,7^{* *}$ & $41,0^{* *}$ & $0,7^{\text {ns }}$ & $3,1^{*}$ & $19,5^{* *}$ & $1,1^{\text {ns }}$ & $15,7^{* *}$ \\
A x B & 6 & $1,8^{\text {ns }}$ & $53,0^{* *}$ & $0,9^{\text {ns }}$ & $2,7^{*}$ & $1,3^{\text {ns }}$ & $2,0^{\text {ns }}$ & $1,3^{\text {ns }}$ \\
\hline CV (\%) & 13,4 & 16,2 & 9,9 & 11,8 & 6,6 & 12,4 & 7,2 \\
Média & 1,3 & 0,5 & 3,5 & 0,05 & 6,7 & 0,01 & 3,6 \\
${ }^{\text {NS }}=$ não significativo; ${ }^{*}=$ significativo a $5 \%{ }^{* *}=$ significativo a 1\% pelo teste F. &
\end{tabular}

Quanto à interação entre os substratos e as concentrações de AIB para as estacas coletadas em estádio reprodutivo observou-se aumento quadrático das médias do número de brotações até a concentração estimada de $400 \mathrm{mg} \mathrm{L}^{-1}$ de AIB quando utilizado o substrato areia (Figura $3 \mathrm{~A}$ ). De modo diferente as médias da massa fresca de brotações diminuíram de modo linear com o aumento das concentrações de AIB no substrato areia (Figura 3B). As médias observadas para ambas as características, quando utilizados os substratos fibra de coco e esterco de caprino, foram inferiores às do substrato areia e não se ajustaram aos modelos linear e quadrático (Figuras 3A e 3B). As menores médias em função do aumento das concentrações de AIB podem ser resultado da ação inibitória resultante da aplicação de níveis acima do adequado para o crescimento vegetativo (TAIZ; ZEIGER, 2013). 

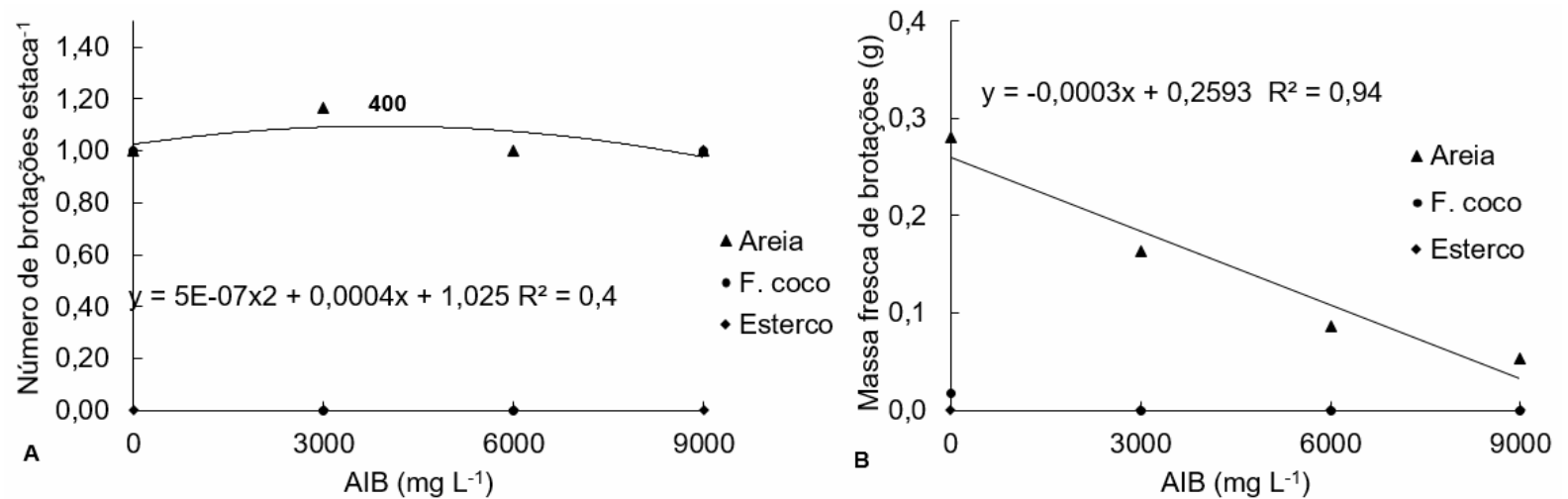

FIGURA 3. Número de brotações (A) e massa fresca de brotações (g) (B) de estacas de umbuzeiro coletadas em estádio e enraizadas em diferentes substratos e concentrações de AIB. Serra Talhada - PE. 2017.

Avaliando-se o desempenho das estacas quanto ao uso dos diferentes substratos, verifica-se que assim como para as estacas coletadas no estádio de dormência, as estacas coletadas no estádio reprodutivo também apresentaram melhores resultados quando utilizada a areia, para a qual foram observados maiores valores de comprimento das brotações, massa fresca e seca de estacas e massa seca de brotações, contudo as médias de massa fresca e seca de estacas com este substrato não diferiram significativamente daquelas quando utilizada a fibra de coco (Tabela 4).

TABELA 4. Médias de comprimento das brotações (CB), massa fresca das estacas (MFE) e massa seca das brotações (MSB) e das estacas (MSE), respectivamente, de estacas de umbuzeiro coletadas em estádio reprodutivo. Serra Talhada - PE. 2017.

\begin{tabular}{cccccc}
\hline Substratos & $\begin{array}{c}\text { CB } \\
(\mathrm{cm})\end{array}$ & $\begin{array}{c}\text { PB } \\
(\%)\end{array}$ & MFE & MSB & MSE \\
\hline Areia & $3,4 \mathrm{a}$ & $8,8 \mathrm{a}$ & $7,0 \mathrm{a}$ & $0,03 \mathrm{a}$ & $3,8 \mathrm{a}$ \\
Fibra de coco & $0,5 \mathrm{~b}$ & $1,7 \mathrm{~b}$ & $6,6 \mathrm{ab}$ & $0,01 \mathrm{~b}$ & $3,7 \mathrm{ab}$ \\
Esterco curtido & $0,0 \mathrm{~b}$ & $0,0 \mathrm{~b}$ & $6,4 \mathrm{~b}$ & $0,00 \mathrm{~b}$ & $3,5 \mathrm{~b}$ \\
\hline
\end{tabular}

Médias seguidas da mesma letra nas colunas não diferem estatisticamente entre si, teste Tukey $5 \%$ de probabilidade.

Em relação ao efeito isolado das concentrações de AIB sobre as estacas coletadas no estádio reprodutivo, verificou-se o decréscimo das médias de comprimento das brotações e da massa fresca e seca das estacas com o aumento das concentrações, de modo que o comprimento diminuiu de forma linear e a massa fresca e seca das estacas de forma quadrática em função das concentrações de AIB (Figuras 4A, 4B e 4C). 

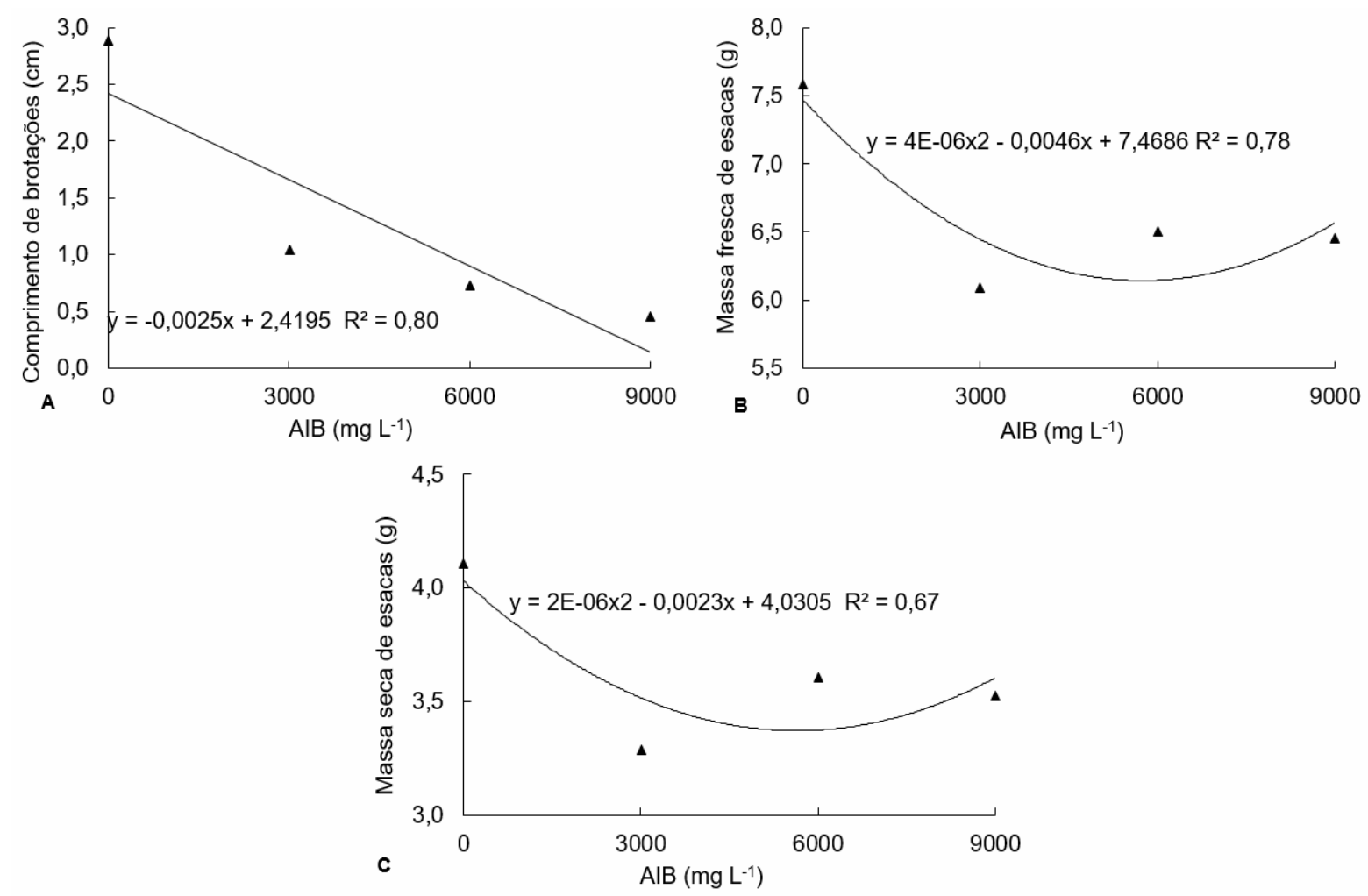

FIGURA 4. Valores de comprimento de brotações (cm) (A) massa fresca (g) (B) e massa seca (g) (C) de estacas de umbuzeiro coletadas em estádio reprodutivo e submetidas a aplicação de diferentes concentrações de AIB. Serra Talhada - PE. 2017.

\section{Experimento 3}

Quando as estacas de umbuzeiro foram coletadas em estádio de crescimento (fevereiro), após 90 dias, não foi observado o desenvolvimento de raízes e de brotações, independente do substrato e da concentração de AIB utilizada. Em virtude do alto vigor da planta na fase de crescimento vegetativo e do grande número de brotações em desenvolvimento, resultante de intensa divisão celular, logo, o teor de citocinina no momento da coleta pode ter afetado negativamente o enraizamento das estacas, de modo que a aplicação de AIB não foi suficiente para promover um adequado balanço entre estes hormônios, visto que, conforme Cheng et al. (2013), é fundamental que haja balanço na razão auxina/citocinina para que ocorra a formação dos primórdios radiculares (CHENG et al., 2013).

\section{CONCLUSÕES}

O substrato areia em associação com a concentração de $9.000 \mathrm{mg} \cdot \mathrm{L}^{-1}$ de AIB, proporcionou melhores resultados de enraizamento e desenvolvimento das brotações nas estacas de umbuzeiro. 


\section{AGRADECIMENTOS \\ Ao CNPq pelo apoio financeiro da bolsa pibic/UFRPE.}

\section{REFERÊNCIAS}

CHENG, Z.J.; WANG, L.; SUN, W.; ZHANG, Y.; ZHOU, C.; et al. Pattern of auxin and cytokinin responses for shoot meristem induction results from the regulation of cytokinin biosynthesis by auxin response factor. Plant Physiology, v.161, n.1, p.240-251, 2013. Disponível em: <https://doi.org/10.1104/pp.112.203166>. doi: 10.1104/pp.112.203166

COOPERCUC. Cooperativa Agropecuária Familiar de Canudos, Uauá e Curaçá. 2012. Disponível em: <www.coopercuc.com.br>. Acesso em: 11 Nov. 2017.

DAS, A.K.; PRASAD, B. Effect of plant growth regulators on rooting survival of air layering in litchi. Advanced Research Journal of Crop Improvement, v.5, n.2, p.126-130, $2014 . \quad$ Disponível em: <http://www.researchjournal.co.in/online/ARJCI/ARJCl\%205(2)/5_126-130_A.pdf>. doi: 10.15740/HAS/ARJCI/5.2/126-130.

DENAXA, N. K.; VEMMOS, S. N.; ROUSSOS, P. A. The role of endogenous carbohydrates and seasonal variation in rooting ability of cuttings of an easy and a hard to root olive cultivars (Olea europea L.). Scientia Horticulturae, v. 143, p. 1928, 2012. Disponível em: <https://doi.org/10.1016/j.scienta.2012.05.026>. doi: 10.1016/j.scienta.2012.05.026

DUTRA, T. R.; MASSAD, M. D.; SARMENTO, M. F. Q.; OLIVEIRA, J. C. D. Indolebutyric acid and substrates on Spondias tuberosa layering. Pesquisa Agropecuária Tropical, v.42, n.4, p.424-429, 2012. Disponível em: <http://dx.doi.org/10.1590/S1983-40632012000400010 > doi: 10.1590/S198340632012000400010

FRANCO, C. F.; PRADO, R. M.; BRAGHIROLLI, L. F.; LEAL, R. M.; PEREZ, E. G.; ROMUALDO, L. M. Uso da poda e de diferentes diâmetros de alporques sobre o desenvolvimento e acúmulo de nutrientes de mudas de lichieira. Revista Brasileira de Fruticultura, v. 27, n. 3, p. 491-494, 2005. Disponível em: <http://dx.doi.org/10.1590/S0100-29452005000300036>. doi: 10.1590/S010029452005000300036

IBGE - Instituto Brasileiro de Geografia e Estatística. Banco de dados do SIDRA PEVS. Disponível em: <https://www.ibge.gov.br/estatisticasnovoportal/economicas/agricultura-e-pecuaria/9105-producao-da-extracao-vegetal-eda-silvicultura.html?\&t=resultados>. Acesso em: 11 Dez. 2017.

LIMA, J.F., SILVA, M.P.L., TELES, S.; SILVA, F., MARTINS, G.N. Avaliação de diferentes substratos na qualidade fisiológica de sementes de melão de caroá (Sicana odorifera (Vell.) Naudim). Revista Brasileira de Plantas Medicinais, v.12, n.2, p.163-167,2010. Disponível em: <http://dx.doi.org/10.1590/S151605722010000200007 >. doi: 10.1590/S1516-05722010000200007. 
MERTENS, J.; GERMER, J.; SIQUEIRA FILHO, J. A.; SAUERBORN, J.Spondias tuberosa Arruda (Anacardiaceae), a threatened tree of the Brazilian Caatinga. Brazilian Journal of Biology, v.77, n.3, p.1-11, 2016. Disponível em: <http://dx.doi.org/10.1590/1519-6984.18715>. doi: 10.1590/1519-6984.18715.

PEÑA, M. L.; ZANETTE, F.; BIASI, L. A. Miniestaquia a partir de minicepas originadas por enxertia de pitangueira adulta. Comunicata Scientiae, v.6, n.3, p.297-306, 2015. Disponível em: <http://dx.doi.org/10.14295/CS.v6i3.817>. doi: 10.14295/CS.v6i3.817.

RIOS, E. S.; PEREIRA, M. C. de; SANTOS, L. S.; SOUZA, T. C.; RIBEIRO, V. G.Concentrações de ácido indolbutírico, comprimento e época de coleta de estacas, na propagação de umbuzeiro. Revista Caatinga, v. 25, n. 1, p. 52-57, 2012. Disponível em: <https://periodicos.ufersa.edu.br/index.php/caatinga/article/view/2113>.

SOUZA, F. X.; ARAÚJO, C. A. T. Avaliação dos métodos de propagação de algumas Spondias agroindustriais. Local: Embrapa agroindústria Tropical, 1999 (EmbrapaAgroindústria Tropical - Comunicado Técnico, 31).

TAIZ, L.; ZEIGER, E. Fisiologia vegetal. 5. ed. Porto Alegre: Artmed, 2013. 954 p.

TECCHIO, M.A.; LEONEL, S.; REIS, L.L.; SIMONETTI, L.M.; SILVA, M.J.R. Stimulate no desenvolvimento de mudas de Kunquat 'Nagami'. Irriga, edição especial p.97-106, 2015. Disponível em: <http://dx.doi.org/10.15809/irriga.2015v1n1p97>. doi: 10.15809/irriga.2015v1n1p97

XAVIER, K. R F; ANDRADE, L. A.; FABRICANTE, J. L.; COELHO, S. M. E.; ASSIS, F. M. N. Impactos pós-fogo na regeneração natural em um fragmento de Foresta ombrófla aberta no município de Areia, Paraíba, Brasil. Revista brasileira de Biociências, v. 9, n. 3 , p. 257-264, $2011 . \quad$ Disponível: <http://www.ufrgs.br/seerbio/ojs/index.php/rbb/article/view/1582/1049>. 